\title{
Is tourism with a low impact on climate possible?
}

\author{
Dr. Jonathan Chenoweth. Centre for Environmental Strategy, University of Surrey, \\ Guildford, Surrey, GU2 7XH, UK. \\ Email: j.chenoweth@surrey.ac.uk; Tel: +44 1483 689096; Fax: +44 1483686671
}

While much of the discussion about the climate change impacts of international travel focuses upon international aviation, all forms of transport result in the emissions of carbon-dioxide. Increased carbon-dioxide emissions also result from the accommodation facilities used by international tourists and the recreational activities they engage in. Scenario analysis of a range of possible international tourist trips shows that the greatest factor determining the carbon-dioxide emissions of a trip is not the mode of transport selected but the distance travelled. The choice of accommodation can also have a significant impact on the total carbon-dioxide emissions resulting from the trip, with low budget options the best choice. Non-air-based recreational activities engaged in by tourists were generally relatively small in their contribution to carbon-dioxide emissions. Scenario analysis shows that carbon-neutral international travel is possible if consideration is given to minimising the carbon impact-travel distances need to be modest, low carbon travel modes such as cycling selected, and low budget accommodation used.

\section{Introduction}

International tourism clearly comes at a significant cost to the environment, with the carbon-dioxide emissions of air travel in particular receiving considerable media attention. However, air travel is not alone in its environmental impact, with other modes of transport also producing carbon-dioxide emissions and other environmental effects, and the impacts from international tourism extend well beyond transport to both the accommodation and recreational activities used by international tourists.

In 2006 there were approximately 846 million international tourist arrivals globally, with tourist arrivals being defined as visitors who stay at least one night in the country visited (World Tourism Organisation, 2007). This was a 5.4 percent increase on the previous year, with just over half (54.4 percent) of these tourist arrivals being in Europe, 20 percent in Asia and the Pacific, and 16 percent in the Americas. Africa and the Middle East each had less than five percent of international tourist arrivals (World Tourism Organisation, 2007).

Each component of international tourism, namely transport, accommodation and the recreational activities carried out by the tourists at their destination results in carbondioxide emissions. While there are many carbon-calculators available on the internet, few of these provide details of the data they are based upon or how the calculations are made, making it difficult to verify the relative impacts of each component of a vacation and thus how to minimise the overall impact. 
This paper will examine the literature on the environmental impacts of international tourism, and seek to quantify the carbon-dioxide emissions resulting from international vacations, breaking down emissions categories into those resulting from transport, accommodation and recreation. Using these data, a range of possible vacation scenarios will then be examined for their relative carbon-dioxide emissions in order to compare the relative climatic impact of different forms of tourism and vacation options. The paper finishes by asking whether climatically responsible international tourism is possible.

\section{The environmental impacts of international travel: Transport}

Many internet based carbon-calculators that allow the assessment of overseas travel focus only upon the transport emissions while ignoring other possible sources of carbondioxide. ${ }^{1}$ Air travel accounts for approximately 46 percent of international tourist arrivals, with road-based transport accounting for 43 percent, water-based transport accounting for 7 percent and rail-based transport accounting for 4 percent (World Tourism Organisation, 2007).

\section{Air travel}

Air travel for tourism has particularly significant climate change implications even though international aviation currently accounts for approximately one percent of total anthropogenic emissions of carbon-dioxide (Olsthoorn, 2001). While the carbon-dioxide emissions resulting from travel are relatively low in absolute terms compared to other anthropogenic emissions and a significant portion of this international aviation is for business purposes, the aviation industry has experienced very rapid growth in recent years. Total passenger numbers travelling by air are forecast to increase at an average annual rate of $4.6 \%$ between 2005 and 2025 (Environmental Unit, 2007).

According to the Tyndall Centre for Climate Change (2005) modelling results suggest that under a contract and converge policy aiming to achieve an atmospheric carbondioxide concentration of $450 \mathrm{ppmv}$, if current growth rates continue aviation emissions by 2050 would exceed the entire permissible emissions for the UK as a whole, and looking at European Union as a whole, aviation emissions would make up 80 percent of the permissible emissions. Even more seriously, carbon-dioxide emissions make up only part of the contribution of aviation to climate change as global warming from aviation also results from contrails, cirrus cloud formation and the emission of other greenhouse gases (Tyndall Centre for Climate Change Research, 2005). While there is considerable scientific uncertainly associated with such effects, such factors may mean that the full climate change effects of aviation may exceed that of the carbon-dioxide emissions alone by a factor of 2.0 to 3.5 times. Due to this great uncertainty, these other factors will not be considered in this paper, with the focus of climatic impacts to be on carbon-dioxide emissions even though this is almost certainly a significant underestimate of the full climatic impact of travel.

\footnotetext{
${ }^{1}$ For example see: http://www.carbonneutral.com/calculators/index_world_calculator.asp, http://www.climatecare.org/, or http://www.co2balance.uk.com/.
} 
The UK Department for Environment Food and Rural Affairs (DEFRA) estimates that a short-haul international air passenger typically is responsible for the emission of 130 grams of carbon-dioxide per kilometre travelled, based upon an average 0.65 load factor for the aircraft and an average journey of $500 \mathrm{~km}$ (DEFRA, 2007a). DEFRA estimates that a long-haul international air passenger is typically responsible for the emission of 105 grams of carbon-dioxide per kilometre travelled, based upon a load factor of 0.797 and an average journey of $3500 \mathrm{~km}$ (DEFRA, 2007a).

\section{Road travel}

Road travel, most frequently by car, also has significant climate change implications. Data from DEFRA suggests that the average car emits 205.9 grams of carbon-dioxide per kilometre travelled (DEFRA, 2007a). The average carbon-dioxide emissions of new cars are declining over time as cars become more efficient, with average emissions of new cars falling from 186 to 164 grams of carbon-dioxide per passenger kilometer between 1995 and 2003 (European Environment Agency, 2006). Even with this gradual reduction in emissions a single person driving to a vacation destination will be responsible for the emission of a significantly larger amount of carbon-dioxide than if they had flown to the same destination, while for a family of four doing the same journey, the car journey will result in much lower emissions per person. Tourists, however, will tend to travel much further by air than by car, thus on trip by trip basis, carbon-dioxide emissions from air travel for international tourism greatly exceed emissions for car travel.

Bus travel is estimated by DEFRA (2007b) to result in emissions of 89 grams per passenger kilometre.

\section{Rail Travel}

Carbon-dioxide emissions from train journeys are affected by the power source of the trains and thus will be region specific. Trains powered by nuclear or hydro generated electricity will have much lower emissions than trains powered by coal generated electricity and both will differ from diesel powered trains. Transport Watch UK (2007) provides an estimate of 55 grams of carbon-dioxide per passenger kilometre for a high speed intercity rail (travelling at $200 \mathrm{~km} / \mathrm{h}$ ) and 86 grams of carbon-dioxide per passenger kilometre for a TGV train $(300 \mathrm{~km} / \mathrm{h})$, in both cases assuming a $30 \%$ load factor.

An alternative estimate of carbon-dioxide emissions from train journeys is provided by the Association of Train Operating Companies (2007) which suggest that rail travel ranges from 54 grams of carbon-dioxide per passenger per kilometre for an electric train to 74 grams of carbon-dioxide per passenger per kilometre for a diesel train. DEFRA (2007b) also provides an estimate for inter-city trains of 60 grams of carbon-dioxide per passenger kilometre but does not specify whether this refers to electric or diesel trains.

\section{Water based travel}

When calculating carbon-dioxide emissions from international ferry-based travel, it is necessary to make decision on how to split allocations between car passengers, foot passengers and freight. Carbon Tracking (2008) suggest allocating emissions on the basis 
of their relative contribution to ferry companies revenue, with foot passengers providing five percent of revenue, cars $40 \%$ and freight $41 \%$. On this basis Carbon Tracking calculates that each car-kilometre of ferry travel generates 1130 grams of carbon-dioxide, while each foot passenger-kilometre generates 141 grams of carbon-dioxide (Carbon Tracking, 2008).

Cruise liner travel is unsurprisingly also very carbon intensive. The Carnival Corporation, a global cruise ship operator with 85 ships, calculates in its 2007 Annual Environmental Management Report that 342 grams of carbon-dioxide per passenger kilometre were emitted from its ships during 2007 (Carnival Corporation, 2008).

\section{Non-fossil fuel based travel}

The lowest carbon dioxide emitting option for travelling significant distances is cycling as this form of transport makes no direct use of fossil fuels. ${ }^{2}$ However, even cycling activity will cause additional carbon dioxide emissions compared to staying at home as the cyclist themselves will expend significant extra energy cycling long distances each day, and thus unless the cyclist wishes to lose weight they will need to increase their food intake. A cyclist weighing $70 \mathrm{~kg}$ who cycles for around five hours per day covering 100 kilometres would expend approximately 3000 additional kilocalories compared to being inactive at home (NHS Direct, 2008). If these additional calories were obtained by eating a high starch food such as bread, this equates to eating $1.2 \mathrm{~kg}$ of bread per day in addition to the person's normal diet. Production of such a quantity of bread would result in the emission of approximately 912 gram of carbon dioxide (Wallén et al., 2004). Thus, a cycle journey results, very approximately, in 9 grams of carbon dioxide emitted per kilometre cycled.

Table 1 summarises the estimations of carbon dioxide emissions from the different modes of transport. With the exception of cycling, a new car with four occupants clearly has the lowest emissions per kilometre travelled, while the train is the best option for one person or a couple.

\footnotetext{
${ }^{2}$ Horse riding results in carbon emissions from stabling and methane emissions, a considerably more potent climate change gas than carbon-dioxide, and it is doubtful whether horse riding would still be practical over long distances due to a lack of the required support services.
} 


\begin{tabular}{|l|l|l|l|}
\hline \multicolumn{2}{|l|}{ Mode of transport } & $\begin{array}{l}\text { Grams / CO } \\
\text { per passenger } \\
\text { kilometre }\end{array}$ & Source(s) \\
\hline Air travel & Short-haul flight & 130 & DEFRA (2007a) \\
\hline & Long-haul flight & 105 & DEFRA (2007a) \\
\hline Road & Average car - single occupant & 206 & DEFRA (2007a) \\
\hline & New car - four occupants & 41 & $\begin{array}{l}\text { European Environment Agency } \\
\text { (2006) }\end{array}$ \\
\hline & Bus & 89 & DEFRA (2007a) \\
\hline & Cycling & 9 & NHS Direct (2008) \& Wallén (2004) \\
\hline Rail & Intercity rail & 55 & Transport Watch UK (2007) \\
\hline & TGV & 86 & Transport Watch UK (2007) \\
\hline & Electric train & 54 & $\begin{array}{l}\text { Association of Train Operating } \\
\text { Companies (2007) }\end{array}$ \\
\hline & Diesel train & 74 & $\begin{array}{l}\text { Association of Train Operating } \\
\text { Companies (2007) }\end{array}$ \\
\hline Water & $\begin{array}{l}\text { Single occupant car passenger on } \\
\text { ferry }\end{array}$ & 1130 & Carbon Tracking (2008) \\
\hline & Foot passenger on ferry & 141 & Carbon Tracking (2008) \\
\hline & Cruise liner passenger & 342 & Carnival Corporation (2008) \\
\hline
\end{tabular}

Table 1: Summary of carbon-dioxide emissions per passenger kilometre of different transport options.

\section{The environmental impacts of international travel: Accommodation}

In most cases international tourism will entail a trip many times greater than a person's regular daily travel patterns. Compared with the journey to a different country, regular daily travel such as the journey to and from work, is relatively insignificant, and for many people will be comparable to the distance travelled to the airport or international rail terminal, or the daily travel while abroad doing recreational activities. Thus, the international journey is in addition to regular travel and causes additional carbon-dioxide emissions than would otherwise have been made when considering the impact of the trip. However, with tourism accommodation things are less straight forward. A person will generally sleep in a bed, shower, eat, and use a range of domestic appliances (either directly or indirectly) whether they stay at home or in a hotel so it is really the marginal change in carbon-dioxide emissions that are important when considering the net impact of the trip.

This net impact will result from the traveller's home continuing to be maintained in their absence, perhaps with a significant reduction in energy consumption depending upon its location, while at the same time the traveller may use facilities that they would not normally use. The largest environmental impact resulting from accommodation probably results from the need to build and maintain facilities for tourists that are in addition to everyday residential accommodation, which will heated (or cooled) and generally 
maintained whether or not they are fully occupied. As with transport, per capita carbondioxide emissions will be minimised when occupancy rates are high.

Other environmental impacts will result from the location in which accommodation facilities are built. Ski resorts, for example, are built in ecologically fragile mountain regions. They are costly to provide services, such as water or sewage, to due their high altitude and extreme weather conditions.

Perhaps because of the difficulty in measuring the marginal impact of tourist accommodation relatively little has been written about this in the environmental literature. The CarbonNeutral Company (2008), a carbon off-setting company states that use of a UK hotel room for one night results in $34.32 \mathrm{~kg}$ of carbon dioxide emissions while an international hotel room results in $33.87 \mathrm{~kg}$ of carbon dioxide emissions. However, they do not qualify how these figures were derived.

Gössling et al (2005) provide an estimate of the carbon dioxide emissions per night per bed resulting from several accommodation options, ranging from $20.6 \mathrm{~kg}$ of carbondioxide per person per night for a hotel stay to $4.0 \mathrm{~kg}$ of carbon-dioxide for a campsite. These estimates are based on the average energy consumption of each type of facility together with numbers of occupants. Thus the actual carbon dioxide emissions will vary significantly depending upon how the energy is produced, with Gössling et al (2005) noting that they contain a moderate degree of uncertainty due to limited data being available.

Estimates of accommodation related energy use are provided by Becken et al (2001) for the New Zealand. Their estimates are given in mega-joules per visitor night, but converted using a global average of 158.4 grams of carbon dioxide per mega-joule (Schafer \& Victor, 1999), their estimates equate to $24.6 \mathrm{~kg}$ of carbon dioxide per hotel night, $6.2 \mathrm{~kg}$ per night for a backpackers and $4.0 \mathrm{~kg}$ per night for camping (Becken et al., 2001)

As with the estimate of the CarbonNeutral Company, the Gössling et al (2005) and the Becken et al(2001) estimates appear to refer to total emissions and not the additional emissions resulting from the hotel stay compared to staying at home. Using data published by DEFRA (2007a), an average UK resident emits 2,687 kg of carbon dioxide per year from their home and their appliance use, thus emitting an average of $7.4 \mathrm{~kg}$ of carbon dioxide per day. Being absent from home will result in a reduction such energy usage although not in most cases to zero since generally there will be appliances left in standby mode that will still consume energy and in many cases heating systems will also be left on in order to prevent pipes freezing. Given this residual use, a temporarily unoccupied house might consume approximately 25 percent of its normal energy consumption, with the amount being higher in winter and lower in summer. For the UK this residual energy usage equates to about 1.9 kilograms for carbon dioxide per night, meaning that camping would result in a net reduction in carbon dioxide emissions and staying in a backpackers hostel would be nearly carbon dioxide neutral due to the savings made at home. 
One further accommodation option available to international tourists concerned about their environmental impacts are home stays, whereby the travellers stay with an ordinary family in their home rather than in facilities specifically constructed (or adapted) and maintained for tourists. The easiest way for this to occur is for travellers to stay with existing friends, however, there are also a number of website which can facilitate travellers staying with local people in the countries they visit by "couch-surfing" sleeping on the couch or in the spare room of a local resident of the area they are visiting. Two of the most popular such site are www.couchsurfing.com and www.hospitalityclub.org, both of which function in a similar manner. These online forums are open for anyone to join by registering and creating for themselves a personal profile. In advance of travelling the traveller will log on to the couch-surfing website and search for people in the place they plan to visit before emailing a selection of the fellow couch-surfers in the place they plan to visit, explaining their travel plans and asking if they can visit or stay. Usually the host will spend time with their guests, often having dinner together before their guests sleep on the sofa or spare bed. Typical accommodation can range from very basic student flats through to rambling country houses with the quality of accommodation obviously dependent on the personal situation of the couchsurfing host.

Under the rules of both the couch-surfing.com and hospitalityclub.org forums, no one is under any obligation to accept any guests they do not want, and no money is allowed to change hands between guest and host, with forum user generally expected to both host and be hosted. Safety is ensured by a feedback system and by examining a potential guest's or host's network of contact and friends within the forum. Many cities, like London or New York have more than a 1000 couch-surfers, other cities, like Gaza, Dili, Pyongyang, Kirkuk, Fallujah, Port Moresby or Honiara have less than ten. Both networks are thoroughly international even if there are more couch-surfers in places with higher levels of internet access.

In carbon dioxide emission terms couch-surfing results in little if any additional carbon emissions in that no accommodation is being provided especially for tourists. Any additional emissions resulting from the hosting of couch-surfing guests should be offset by a reduction in the guests own home being temporarily unoccupied. In addition to the environmental benefits of couch-surfing, the tourists themselves generally save money by avoiding accommodation costs. However, the greatest benefit of couch-surfing for tourists is the more meaningful contact and understanding that it facilitates with the local community they are visiting than is normally possible when visiting a foreign country as a tourist.

Table 2 summarise the net carbon dioxide emissions for the different accommodation options. Net emissions refers to the change in carbon dioxide emissions of a stay in a hotel compared staying at home and assumes that the maintenance of the traveller's house in the UK will result in the emission of $1.8 \mathrm{~kg}$ of carbon-dioxide, a 75 percent reduction from the average emissions of $7.4 \mathrm{~kg}$ per day - thus saving $5.6 \mathrm{~kg}$ of carbondioxide per day to off-set against the emissions from the vacation accommodation. 


\begin{tabular}{|l|l|l|}
\hline Accommodation & $\begin{array}{l}\text { Net carbon-dioxide emissions } \\
\text { (kilograms per person-stay per } \\
\text { night) for a UK resident }\end{array}$ & Source \\
\hline Hotel room & 28.3 & CarbonNeutral Company (2008) \\
\hline Hotel room & 15.1 & Gössling et al (2005) \\
\hline Hotel room & 19.1 & Becken et al (2001) \\
\hline Hotel room (average) & 20.8 & \\
\hline Backpackers hostel & 0.55 & Becken et al (2001) \\
\hline Camping & -1.6 & $\begin{array}{l}\text { Gössling et al (2005) \& Becken et al } \\
(2001)\end{array}$ \\
\hline Couch-surfing & 0 & \\
\hline
\end{tabular}

Table 2: Net carbon dioxide emissions resulting from different forms of tourist accommodation.

\section{The environmental impacts of international travel: Recreation}

Becken and Simmons (2002) calculated the average energy use per tourist for different tourism related recreational activities and attractions in New Zealand. They divided activities into three categories, namely attractions, entertainment, and activities. Attractions included things such as museums and art galleries, amusement parks, breweries and natural attractions, such as hot pools. The attractions they considered ranged per tourist between 95 grams of carbon dioxide for a visitor centre and $27.6 \mathrm{~kg}$ of carbon dioxide wine trail when converted from MJ values using global averages of grams of carbon-dioxide per MJ of energy. Entertainment included cinema, live theatre, night clubs, casinos and shopping and ranged between 127 grams of carbon-dioxide for a tourist shop and $6.2 \mathrm{~kg}$ of carbon-dioxide for an entertainment complex. Activities included things such as sky diving, heliskiing, diving, sailing, mountain biking, rock climbing, fishing and guided walking, which ranged from 95 grams of carbon dioxide for a horse riding operator and $459.8 \mathrm{~kg}$ of carbon dioxide for a fishing operator offering helicopter trips (Becken \& Simmons, 2002).

The average attraction was responsible for 950 grams of carbon dioxide per tourist, while for entertainment the average was 1426 grams and for activities the average was $15.2 \mathrm{~kg}$ of carbon dioxide. For activities in particular, the nature of the activity had a very significant impact on carbon dioxide emissions. Air based activities resulted in $70 \mathrm{~kg}$ of carbon dioxide per tourist while adventure based activities resulted in a much more modest $5.5 \mathrm{~kg}$ of carbon dioxide on average.

The carbon dioxide estimates for activities derived by Becken and Simmons (2002) were calculated based on a survey of tourism related operators in New Zealand and thus only consider organised activities or maintained venues. A mountain biking operator, for example, will have to run some form of administrative office and may transport bikes and riders to and from the start of an organised ride, with each of these resulting in carbondioxide emissions. However, the same activity carried out by a group of individuals on their own in some situations would result in no direct carbon dioxide emissions if they 
were to go from and return to their hotel on their own. Similarly, a group of tourists visiting some wineries directly on route to their vacation destination would result in far fewer emissions than identified by Becken and Simmons (2002) for a winery tour run by a tourist operator. See Table 3 for a summary of estimates of carbon-dioxide resulting from international tourist recreation.

\begin{tabular}{|l|l|l|l|}
\hline Activity & $\begin{array}{l}\text { Average carbon-dioxide } \\
\text { emissions (kg) per tourist } \\
\text { participant / visitor }\end{array}$ & $\begin{array}{l}\text { Highest carbon-dioxide } \\
\text { emission (kg) per tourist } \\
\text { participant / visitor from survey } \\
\text { sample }\end{array}$ & $\begin{array}{l}\text { Lowest carbon-dioxide } \\
\text { emission (kg) per tourist } \\
\text { participant / visitor from } \\
\text { survey sample }\end{array}$ \\
\hline Attractions & 0.950 & 27.6 & 0.095 \\
\hline Entertainment & 1.426 & 6.2 & 0.127 \\
\hline Activities (all) & 15.2 & 459.8 & 0.095 \\
\hline -Air based activities & 70 & & \\
\hline -Adventure based activities & 5.5 & & \\
\hline
\end{tabular}

Table 3: Carbon-dioxide emissions resulting from tourist recreation. (Source:Becken \& Simmons, 2002)

\section{Emissions scenarios for international vacations}

Using the previously calculated data it is possible to calculate the net change in carbon dioxide emissions of a range of vacation options compared to staying at home in order to identify the relative significance of the travel mode choice, accommodation choice and activity choice.

To permit comparison, some basic assumptions need to be made. Each scenario will be for two people travelling together with the point of origin being suburban London. For all scenarios except 1 , it is assumed that they will consume a similar amount of food to normal. Local transport usage at the destinations for self organised activities is assumed to approximately balance local transport usage had they stayed at home, such as commuting. 


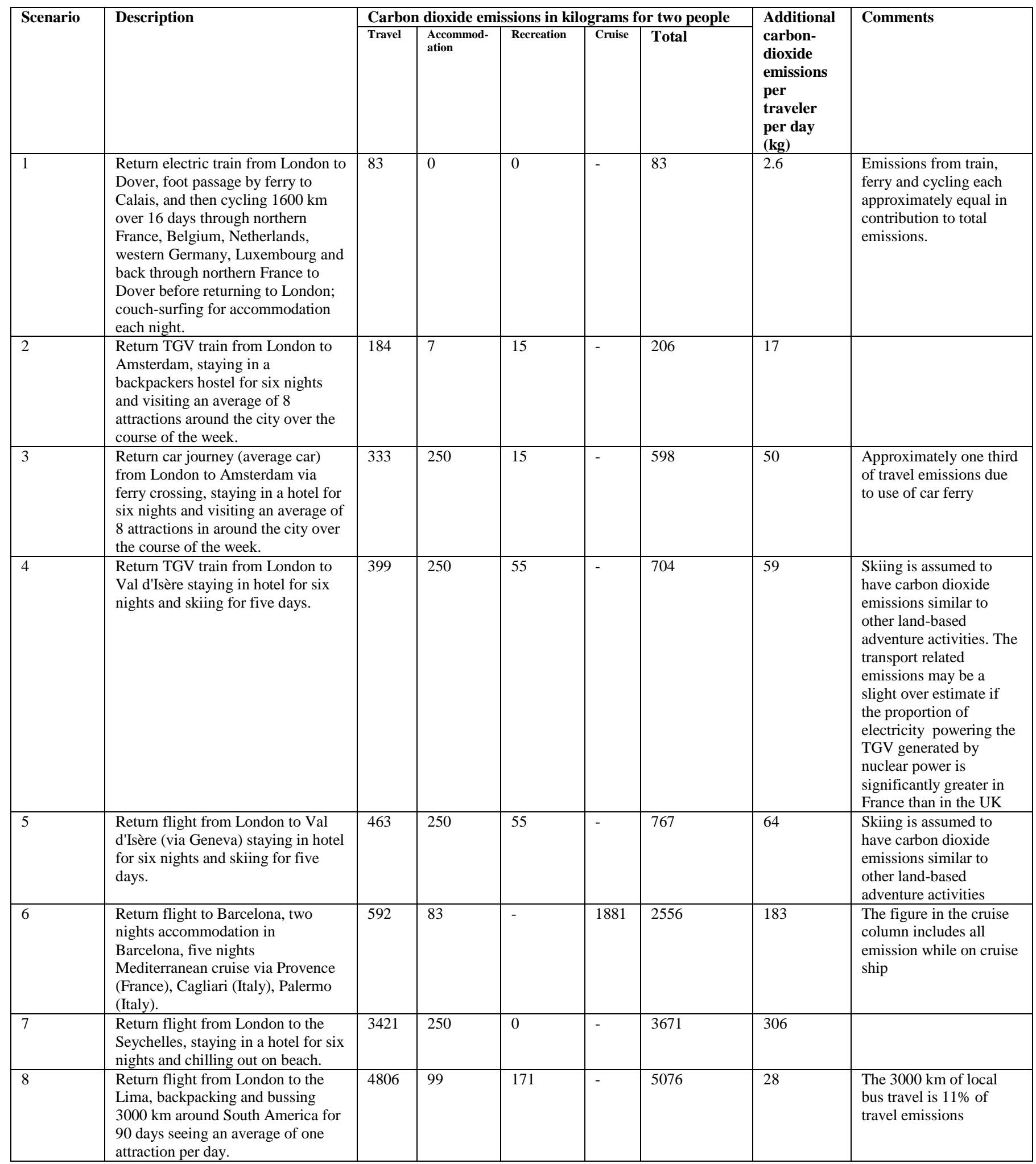

Table 4: Transport scenarios showing the carbon-dioxide emissions from a range of tourist trip options compared to the carbon-dioxide emissions resulting from staying at home. 


\section{Discussion:}

A typical UK resident staying at home, as noted in the accommodation section, will produce on average $7.4 \mathrm{~kg}$ of carbon dioxide each day from their house and its appliances. The average resident travels $13.39 \mathrm{~km}$ to work, thus doing a round trip of $26.78 \mathrm{~km}$ each weekday, with the overwhelming majority of such trips being by car (National Statistics, 2007). The home-based emissions were taken into consideration when calculating the accommodation emissions and it was assumed that the tourist would do local travel at their destination approximately comparable to what they would have done at home, hence the calculated emissions for each scenario are in addition to existing personal emissions. The scale of these existing personal emissions, which are slightly in excess of ten kilograms per person per day, are useful for providing a benchmark to compare against the resulting emissions for each travel scenario.

Scenario 1 clearly had the lowest level of carbon-dioxide emission -83 kilograms in total and 2.6 kilograms per person per day, which itself was probably a slight overestimate since local travel the destinations covered on the trip would almost certainly be carried out by bicycle and hence would be lower than an average person's daily regular travel back in the UK, possibly even cancelling out the $2.6 \mathrm{~kg}$ of emissions resulting from the train, ferry and cycling. However, even without allowing for this probable overestimation, $2.6 \mathrm{~kg}$ of carbon-dioxide per person per day is a modest increase on the benchmark for comparison of ten kilograms per person per day.

Scenarios 2 and 3 both describe a very similar trip, scenario 2 being the more luxurious flying to Amsterdam and staying in hotel and scenario 3 being the budget version taking the train to Amsterdam and staying in a backpackers hostel. The majority of the difference in the two scenarios, however, is due not to driving rather than taking the train, but due to staying in a hotel rather than a backpackers hostel, showing how with relatively short trips, the choice of accommodation has a much greater impact on carbondioxide emissions than the choice of transport. Scenario 2 had a per person carbondioxide emission increase of 17 kilograms per day, thus resulting in a nearly tripling of emissions, while scenario 3 resulted in additional emissions of $50 \mathrm{~kg}$ per person per day, a six-fold increase.

Scenarios 4 and 5 also described a similar trip, namely a week's skiing at Val d'Isère. In both scenarios hotel accommodation was assumed but in scenario 4 the primary form of transport was TGV train while in scenario 5 air transport was used. Both of these scenarios resulted in very similar carbon emissions, suggesting that it is not so much a case that flying is significantly worse on a per kilometer basis than driving or taking the train, but rather, that flying is worse for the environment because it facilitates much longer distance travel. The per capita daily additional emissions for scenario 4 were 59 kilograms while for scenario 5 they were 64 kilograms. 
Scenario 6, a week-long Mediterranean cruise, resulted in three times the additional emissions of the Alpine skiing trip and per traveller per day emissions were 18 times the benchmark figure for staying at home. While the greater flight distance had some impact, the major reason for the significant increase in carbon-dioxide emissions compared to skiing was due to the cruise itself, which is not a particularly carbon-efficient form of transport or accommodation.

Scenarios 7 and 8 both were trips involving long intercontinental flights but scenario 7 was a week long visit to a beach resort in the Seychelles while scenario 8 was a three month backpacking journey around South America. On a trip by trip basis, the backpacking journey around South America was by far the worst, resulting in more than five tonnes of carbon-dioxide, however, on a per day basis, this scenario resulted in approximately a four-fold increase compared to staying at home due to the five tonnes being averaged over a long period of time. Thus, if the Seychelle visiting tourists of scenario 7 had returned to London and for the next three months been responsible for the average carbon-dioxide emissions of a UK resident, they would still have produced less carbon-dioxide than the South-American visiting backpackers of scenario 8. Scenarios 7 and 8 show that intercontinental flights inevitably produce very carbon intensive tourist trips regardless of any other factor.

\section{Conclusions}

The data collected and the range of travel options considered show that international tourism does not inherently result in large increases in carbon dioxide emissions. Environmentally concerned travellers have options open to them that allow carbonneutral or nearly carbon-neutral travel and as an added benefit, such travel options tend to be much lower in cost and provide significantly greater interaction with the local people in the countries being visited than other forms of travel generally permit. Cycling is clearly the most carbon-friendly practical means of travelling internationally (and has significant additional health benefits) but travelling by train, plane or car a similar (relatively modest) distance is not substantially more carbon intensive when compared to the carbon emissions resulting from staying at home. The most important factor determining carbon-dioxide emissions is the total distance travelled, making intercontinent travel very problematic from a climate change perspective.

With trains, planes and cars, the load factor is critical in determining carbon-dioxide emissions per traveller, although with planes and trains, this is outside of the control of

the traveller. Car travel would have come out significantly better than air or train travel in the scenario analysis if three passengers rather than one had been assumed, just as plane or train travel would have come out better than the other two if full occupancy had been assumed when the basic carbon-dioxide emission rates per passenger-kilometre were calculated.

With short-distance travel, choice of accommodation and recreational activities becomes very important. Camping, couch-surfing and backpacker hostel accommodation are good 
choices from a carbon (and financial) perspective and can thus contribute to low carbon tourism. The environmental benefits of choosing one of these low carbon alternatives over hotel accommodation can more than outweigh the additional carbon-dioxide emissions from using a less carbon efficient form of transport for short-distance trips.

Recreational activities were shown by the scenario analysis to generally be relatively small in their carbon-dioxide emissions compared to transport and accommodation related emissions. However, where tourists engage in air-based recreational activities, such activities could be expected to be relatively significant as a total proportion of the emissions resulting from a trip, except trips involving intercontinental travel.

\section{Author bios:}

Dr. Jonathan Chenoweth is a lecturer in Natural Resources Management in the Centre for Environmental Strategy, University of Surrey. He researches on environmental policy and sustainable development in developed and developing regions, including in the UK and elsewhere in Europe, the Middle East and Africa. In January 2008 Dr. Chenoweth cycled and couch-surfed $1650 \mathrm{~km}$ across northern France, Belgium, Netherlands, western Germany, and Luxembourg with a friend, demonstrating that essentially carbon-neutral international travel is both possible and fun.

\section{References:}

Association of Train Operating Companies.2007. Baseline energy statement - energy consumption and carbon dioxide emissions on the railway. London: Association of Train Operating Companies. http://www.atoc.org/index.asp

Becken, S., Frampton, C., \& Simmons, D.2001. "Energy consumption patterns in the accommodation sector-the New Zealand case." Ecological Economics, 39, No: 371386.

Becken, S., \& Simmons, D.2002. "Understanding energy consumption patterns of tourist attractions and activities in New Zealand." Tourism Management, 23, No: 343-354.

Carbon Neutral Company.2008. The CarbonNeutral Company. London: CarbonNeutral Company. http://www.carbonneutral.com/sbc/sbchelp.asp

Carbon Tracking.2008. A study of the carbon footprint of cartransport with Irish Ferries. Inagh: Carbon Tracking. http://www.carbontracking.com/reports/irish_ferries_emissions_calculation.pdf 
Carnival Corporation.2008. Environmental Management Report: Fiscal Year 2007. Miami: Carnival Corporation \& PLC. http://media.corporateir.net/media_files/irol/14/140690/Environmental_Management_Report_FY07.pdf

Department for Environment Food and Rural Affairs.2007a. Act on CO2 Calculator: Public Trial Version: Data, Methodology and Assumptions Paper. London: Department for Environment Food and Rural Affairs. http://www.defra.gov.uk/environment/climatechange/uk/individual/pdf/actonco2-calcmethodology.pdf

Department for Environment Food and Rural Affairs.2007b. Guidelines to Defra's GHG conversion factors for company reporting: Annexes updated June 2007. London: Department for Environment Food and Rural Affairs. http://www.defra.gov.uk/environment/business/envrp/pdf/conversion-factors.pdf

Environmental Unit.2007. ICAO Environmental Report. Montreal: Environmental Unit of the International Civil Aviation Organization (ICAO). http://www.icao.int/icao/en/env/pubs/env_report_07.pdf

European Environment Agency.2006. Transport and environment: Facing a dilema. Copenhagen: Office for Official Publications of the European Communities. http://reports.eea.europa.eu/eea_report_2006_3/en/term_2005.pdf

Gössling, S., Peeters, P., Ceron, J., Dubois, G., Patterson, T., \& Richardson, R.2005. "The eco-efficiency of tourism." Ecological Economics, 54, No: 417-434. National Statistics.2007. 2001 Census. London: HMSO.

NHS Direct.2008. Calculate calories burned by exercise. London: National Health Service Direct. http://www.nhsdirect.nhs.uk/magazine/interactive/calories/index.aspx

Olsthoorn, X.2001. "Carbon dioxide emissions from international aviation: 1950-2050." Journal of Air Transport Management, 7, No: 87-93.

Schafer, A., \& Victor, D.1999. "Global passenger travel: implications for carbon dioxide emissions." Energy, 24, No: 657-679.

Transport Watch UK.2007. Facts sheet 5(b) - Carbon emissions: high speed rail and air compared. Northampton: Transport Watch UK. http://www.transwatch.co.uk/transportfact-sheet-5b.htm

Tyndall Centre for Climate Change Research.2005. Decarbonising the UK: Energy for Climate Conscious Future. Norwich: Tyndall Centre for Climate Change Research. http://www.tyndall.ac.uk/media/news/tyndall_decarbonising_the_uk.pdf

Wallén, A., Brandt, N., \& Wennersten, R.2004. "Does the Swedish consumer's choice of food influence greenhouse gas emissions?" Environmental Science and Policy, 7, No 6: 525-535. 
World Tourism Organisation.2007. Tourism Highlight: 2007 Edition. Madrid: World Tourism Organisation. http://www.unwto.org/index.php 